\title{
BRAIN SPECT IN THE PRE-SURGICAL EVALUATION OF EPILEPTIC PATIENTS
}

\author{
PRELIMINARY RESULTS
}

\author{
CARLOS A. BUCHPIGUEL * - ARTHUR CUKIERT**- FAUSTO H. HIRONAKA * \\ GIOVANI G. CERRI*- ALVARO E. A. MAGALHAES * - RAUL MARINO JR.**
}

SUMMARY - Pre-surgical evaluation of epileptic patients consists of neurological examination, intensive electroencephalographic (EEG) monitoring and anatomical studies (CT and MRI). Functional methods such as PET and SPECT imaging are now used more frequently. We have studied pre-operatively 15 adult epileptıc patients (8 female, 7 male) using a rotational scintillation camera interflaced to a dedicated computer. The tomographic images were obtained 15 minutes after intravenous injection of $99 \mathrm{mTc}$.HMPAO. All had MRI scanning and intensive EEG monitoring which generally included seizure recording. Five patients had progressive lesions (3 meningiomas, 2 astrocytomas). In 10 patients, neuroradiological studies did not show the presence of progressive lesions (2 normal scans and 8 cases with inactive lesions). Two patients with meningioma showed hypoperfusion at the lesion site while the third patient had a marked hyperperfusion which might correlate with the clinical diagnosis of epilepsia partialis continua. In the astrocytoma patients SPECT scans showed hypoperfusion at the lesion site. Data obtained from the 10 patients without progressive CNS lesions showed: (a) in 4, SPECT findings correlated well with the anatomical findings; (b) in 5 instances, SPECT was able to disclose additional functional deficits; (c) in one case, there was no SPECT correlate of a discrete anatomical lesion. In 5 of these cases with no progressive lesions $(n=10)$ SPECT findings were useful as a complementary tool in determining the clinical or surgical management of these patients. Despite the small number and heterogenicity of the present sample, SPECT seems to be an useful tool as part of the clinical workup of epileptic patients who are candidates for epilepsy surgery.

KEY WORDS: SPECT, epilepsy, surgery, pre-operative evaluation.

\section{SPECT cerebral na avaliação pré-cirúrgica de pacientes epilépticos}

RESUMO - A avaliação pré-operatória de pacientes epilépticos consiste basicamente de exame neurológico, monitorização intensiva de EEG e estudos anatômicos (CT e RMN). Métodos funcionais como PET e SPECT têm sido utilizados mais frequentemente nos últimos anos. Foi realizada a investigação pré_operatória em 15 pacientes epilépticos adultos (8 mulheres, 7 homens) utilizando câmara de cintllação rotacional acoplada a computador. As imagens tomográficas foram obtidas 15 minutos apbs a injeção de 99mTC HMPAO. Todos os pacientes foram submetidos a RMN e monitorização intensiva de EEG, que geralmente inclui registros lctais. Cinco pacientes possuiam lesóes expansivas ( 3 meningeomas e 2 astrocitomas). Em 10 pacientes, os estudos neurorradiológicos não mostraram presença de lesões expansivas (2 normais e 8 com lesões inativas). O estudo de 2 pacientes com meningeomas mostrou presença de hipoperfusão ao nível da lesão, enquanto em um terceiro caso marcada hiperperfusão foi detectada e, neste paciente, provavelmente correlacionava-se quadro de epilepsia partialis continua. Nos pacientes com astrocitomas, os exames de SPECT mostraram hipoperfusão no local da lesão. Os dados obtidos em pacientes não portadores de lesరes expansivas do sistema nervoso mostraram: (a) em 4 casos os achados de SPECT. correlacionaram-se bem aos achados

Centro de Medicina Nuclear do Departamento de Radiologia (*) e Disciplina de Neurocirurgia do Departamento de Neurologia (**) da Faculdade de Medicina da Universidade de São Paulo (FMUSP).

Dr. Carlos Alberto Buchpiguel - Centro de Medicina Nuclear, FMUSP - Caixa Postal 22082 01499 são Poulo SP - Brasil. 
anatômicos; (b) em 5 casos, os achados de SPECT mostraram déficits de fluxo adicionais a lesão anatomica; (c) em um caso, não houve correlação entre os achados de SPECT e uma pequena lesão anatômica. Em 5 casos com lesões não progressivas ( $n=10)$ os achados de SPECT foram úteis na determinação da conduta clínica ou cirúrgica. Apesar do pequeno número e da heterogeneidade da presente amostra, o SPECT parece ser importante método complementar no arsenal clínico-propedêutico de pacientes epilépticos candidatos a cirurgia.

PALAVRAS CHAVES: SPECT, epilepsia, cirurgia, avaliação pré-operatória.

Epilepsy is a chronic neurologic disease characterized by recurrent ictal episodes derived from the synchronous hyperactivity of cortical neuronal populations. The main clinical workup of epileptic patients comprises a seizure history, neurological examination, electroencephalographic (EEG) recordings and neuroradiological studies (CT and MRI). 15-20\% of the patients with epilepsy are medically refractory to the current anti-epileptic drugs regimens and are potential candidates for epilepsy surgery. In this selected population, accurate lateralization and localization of the epileptogenic region is mandatory. Functional methods (PET and SPECT) have been used in an increasing frequency as a tool in the pre-surgical evaluation of epileptic patients in the last years 2,3. PET and SPECT studies have shown that the epileptic regions were characterized by hypoperfusion/hypometabolism (hypo/hypo) patterns in the interictal period, even when there was no anatomical correlate in the neuroradiological studies. This hypo/hypo region is often bigger than the actual epileptic focus 6-8.

Our preliminary SPECT (single photon emission computerized tomography) scanning results obtained from adult epileptic patients who were candidates for epilepsy surgery are described in this paper.

\section{METHODS}

Fifteen adult patients (eight males, seven females) who were candidates for epilepsy surgery were submitted to interictal SPECT scanning. One patient had an ictal and another one an post-ictal study. Five patients had progressive central nervous system (CNS) diseases (three meningiomas and two astrocytomas). In ten patients the neuroradiological studies did not disclose any progressive lesion (two normal and eight with inactive lesions scans) (Table 1).

The brain SPECT images were obtained after intravenous injection of $740 \mathrm{MBq}$ (20 mCi) of $99 \mathrm{~m}$ Tc_hexamethylenopropyloximeamine (HMPAO) (Ceretec/Amersham). The vilals were reconstituted using $5 \mathrm{ml}$ of $99 \mathrm{mTc}$-pertecnetate solution with activity not superior to $1295 \mathrm{MBq}$ (35 mCi). Radiochemical controls (mean 86\%) were obtained. All patients received $500 \mathrm{mg}$ of potassium perchlorate 30 minutes prior to the injection. Visual, sensitive or auditive stimuli were avoided during radiopharmaceutical administration.

Tomographic images were obtained 15 minutes after injection, using a rotational single-head scintilation camera (Siemens model Orbiter) interfaced to a dedicated computer (Microdelta) and equiped with a high resolution colimator. The image data were acquired for 30 seconds per stop, for a total of 64 stops, using a 360 degrees rotation over the circumference of the head. The matrix size used was $64 \times 64$ and a proper center of rotation and Ilood uniformity corrections were applied. Transaxial, sagittal and coronal slices were obtained by proccessing procedures by means of a Butterworth filter. The slice size was 1 pixel or $6 \mathrm{~mm}$ thick.

\section{RESULTS}

SPECT data can be sumarized as in the Table 1. Two patients with meningioma showed hypoperfusion at the lesion site while the third patient had a marked hyperperfusion which might correlate with the clinical diagnosis of epilepsia partialis continua (Fig. 1).

In the patients with astrocytoma, SPECT scans showed hypoperfusion at the lesion site. Data obtained from the ten patients without progressive CNS lesions showed: (a) in four SPECT findings correlated well with the anatomical findings: (b) in five instances, SPECT was able to disclose additional functional deficits (Fig. 2); (c) in one case, there was no SPECT correlate of a discrete anatomical lesion. In five of these cases with no progressive lesions $(n=10)$ SPECT findings were useful as a complimentary tool in determining the clinical or surgical management of these patients. In one case a post_ictal SPECT study disclosed an enlarged hypoperfused area when compared to a previous inter-ictal exam (Fig. 3). 

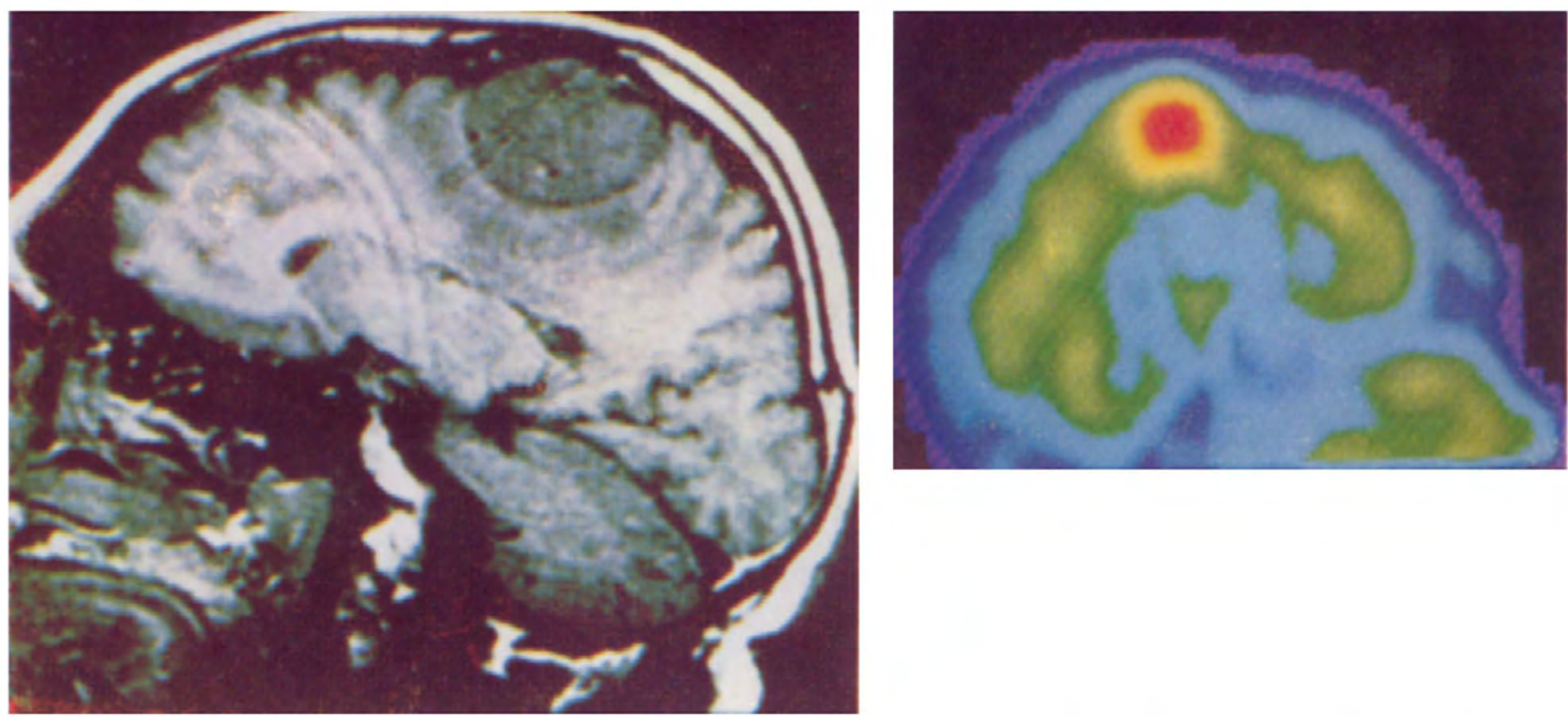

Fig. 1 - Sagittal MRI (left) and ictal SPECT (right) imagens in a patient with meningioma showing a hyperperfusion pattern.
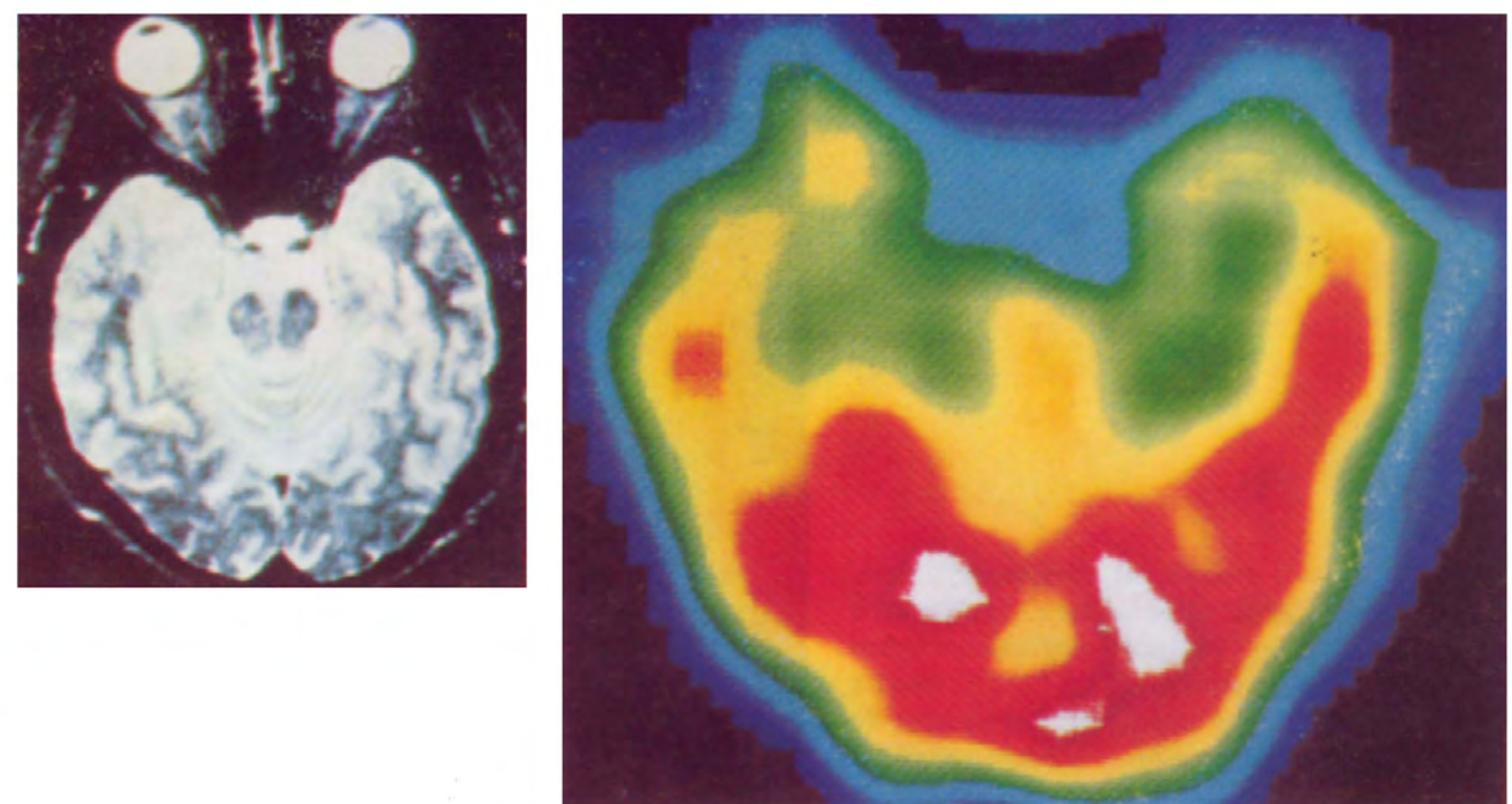

Fig. 2 - Right temporal lobe hypoperfusion in a patient with a normal MRI. Normal transverse MRI slice (left) and abnormal interictal SPECT study (right). 

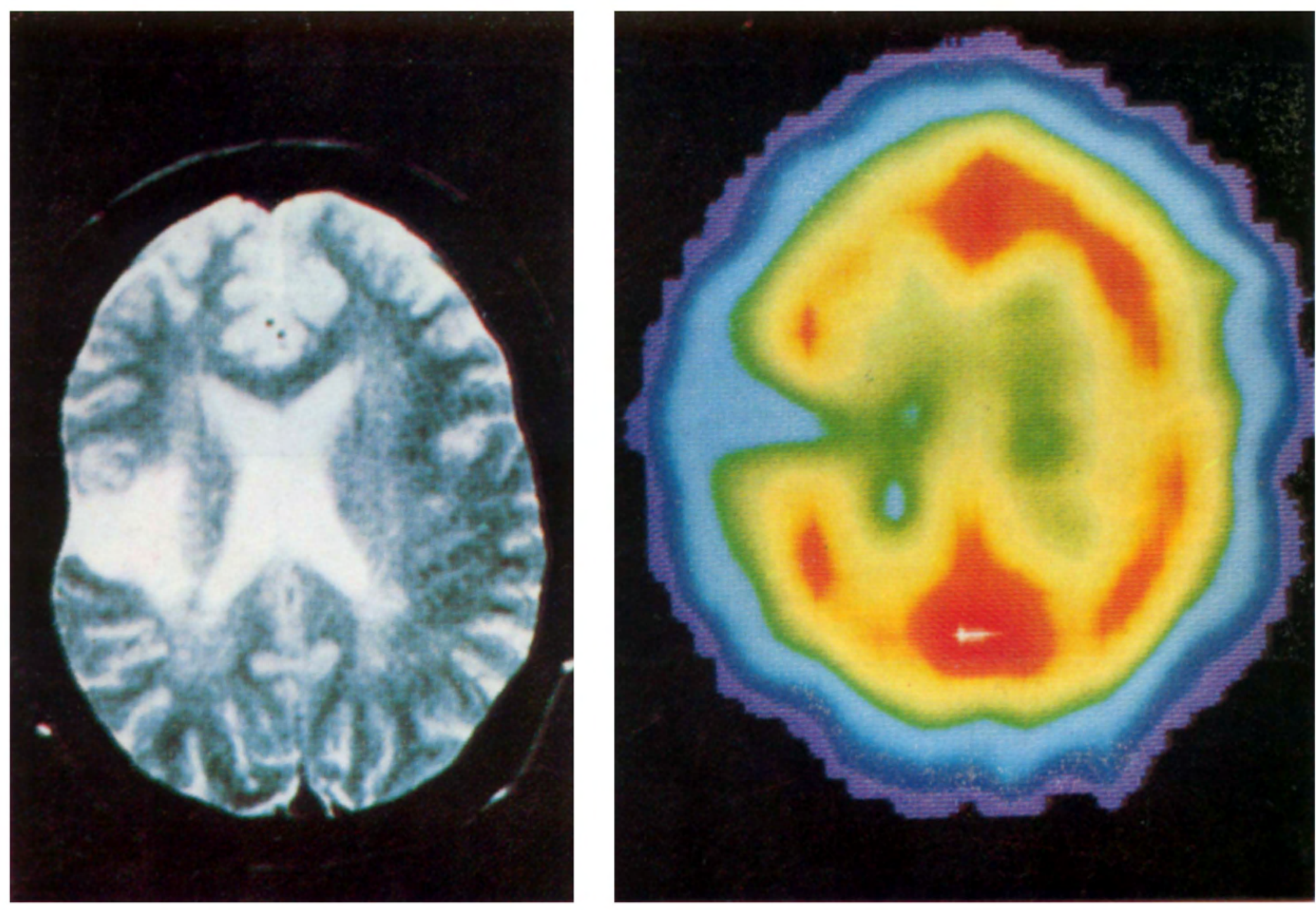

Fig. 3 - Post-ictal hypoperfusion. Transverse MRI slice shows an inactive lesion at the temporo-parietal region (above left); interictal SPECT shows an hypoperfused area corresponding to the structural seion (above right); post-ictal SPECT shows an increase in the hypoperfused area that now includes bigger areas of the fronto-parietal region (below).

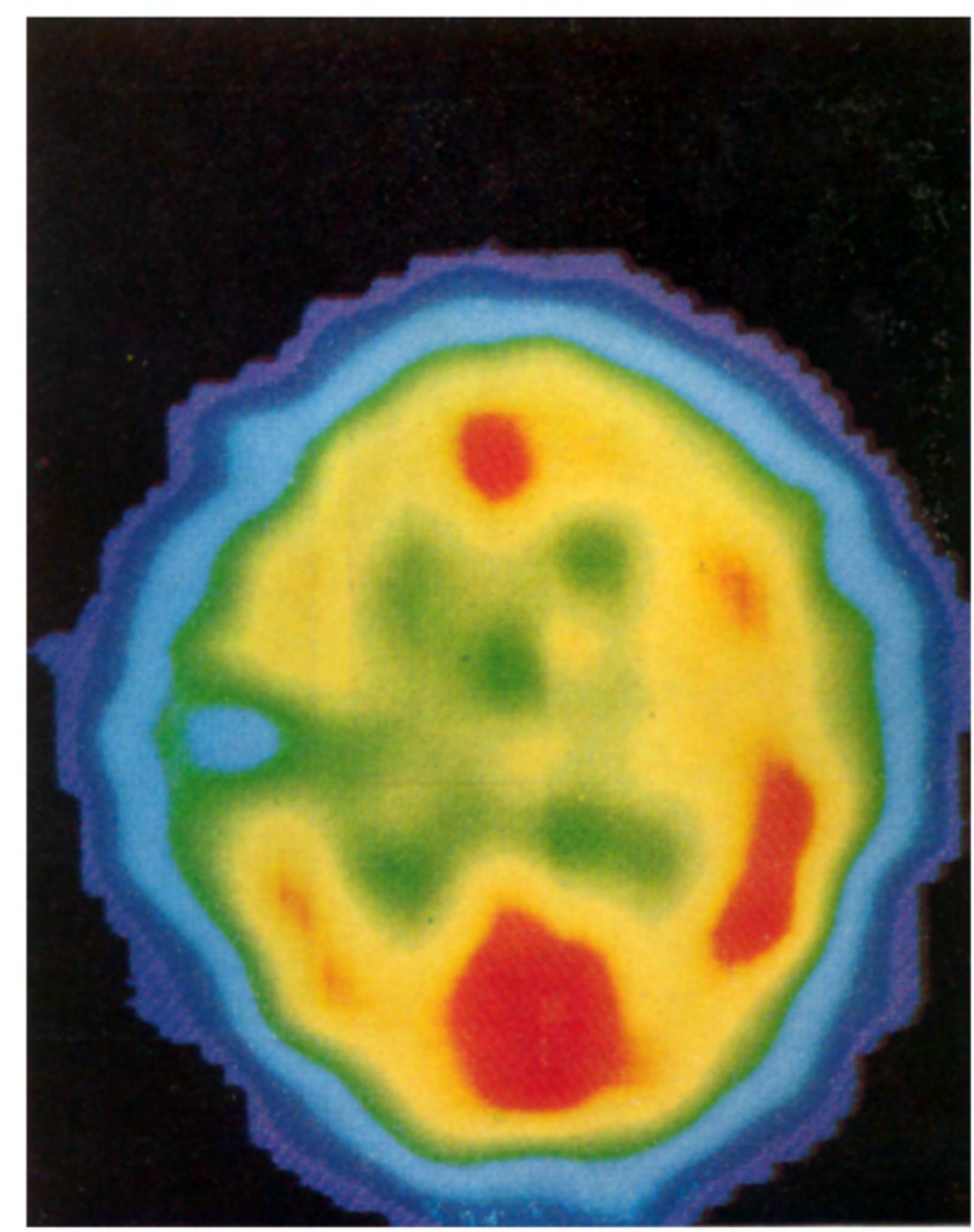


Table 1 - Clinical and imaging data.

\begin{tabular}{rllll}
\hline Pt & Clinical & EEG & \multicolumn{1}{c}{ MRI } & SPECT \\
\hline 1 & SPS & RF & RF Meningioma & RF Hypoperfusion \\
2 & SPS & RF, RO, LO & RO Inactive lesion & RFTPO, LO Hypoperfusion \\
3 & SPS & RT & Normal & RT Hypoperfusion \\
4 & CPC & RT, LT & LT Astrocytoma & LT Hypoperfusion \\
5 & & RF & RF Inactive lesion & RF, LC Hypoperfusion \\
6 & CPC & LT & LT Inactive lesion & -Inter-ictal: \\
& & & & LTP Hypoperfusion \\
& & & -Post-ictal \\
7 & SPS & LFP & LFP Meningioma & LTP more intense hypoperfusion \\
8 & CPC & LF, RT & LF Inactive lesion & LFP Hypoperfusion \\
9 & SPS & LFTPO & L Cerebral hemiatrophy & LF Hypoperfusion \\
10 & CPC & LT, RT & LT Inactive lesion & LF Hypoperfusion \\
11 & CPC & LT & Normal & LT Hypoperfusion \\
12 & CPC & RT & RT Meningioma & RTPO Hypoperfusion \\
13 & CPC & RT, LT & RT Astrocytoma & RT Hypoperfusion \\
14 & CPC & RT & FT Dysgenesis & Normal \\
15 & SPS & LF & LF Dysgenesis & LF Hypoperfusion \\
\hline & & & & \\
\hline & & &
\end{tabular}

Pt, patients; Clinical, seizure pattern; SPS, single partial seizure; CPS, complex partial seizure; $E$, frontal; $P$, parietal; $T$, temporal: $O$, occipital; $C$, cerebellum; L, left; $R$, right.

\section{COMMENTS}

Epilepsy is a disease caused by the overactivity of neuronal populations. On the other hand, functional methods have shown that the epileptic focus is characterized by a hypo/hypo patttern in the interictal state. This would suggest an apparent lack of consistency between the actual pathophysiology of epilepsy and the results obtained from functional studies. The fact that the epileptogenic region is a lesionated area should be taken into account and should explain the previous findings 9 . The hypo/ hypo region seen in these cases is often larger than the actual epileptogenic area 1 Cortico-cortical inhibition in the periphery of the focus and an expanded area of functional derangement surrounding the epileptogenic foci might be involved in this process. On the contrary, ictal patterns were characterized by an hyperperfusion/hypermetabolic pattern (hyper/hyper) and correlated well to a marked synchronization and hyperactivity of large neuronal populations 4. Post-ictal studies have shown a marked and/or enlarged hypo/hypo pattern in the epileptic focus. Studies performed immediatly after the ictus might show hyper/hyper zones surrounded by hypo/hypo ones 5 .

Our studied population was heterogeneous. Five cases had progressive lesions Such cases were commonly associated to brain edema. The analysis of functional data obtained from SPECT in such patients was difficult and should be considered carefully. On the other hand, the analysis of the cases with no progressive lesions $(n=10)$ yielded a high diagnostic rate.

Ictal studies are more difficult to obtain than interictal ones. In this series, only one patient with epilepsia partialis continua associated to a meningioma had an ictal SPECT which showed a marked hyper/hyper pattern.

Post-ictai studies are more easily obtained but their results can vary widely according to the timing of the injection of the tracer. In case 6 , an enlargement of the interictal hypo/hypo previously determined area was seen post-ictally.

In five cases with no progressive lesions $(n=10)$ SPECT was an important item in the presurgical management protocol and was used to determine a medical and/or surgical procedure. 
Despite the fact that PET scanning yields a better image resolution than SPECT, the latter has been being used in an increasing frequency in the last years. It is an easier method and certainly a less expensive one. The above data suggest that SPECT is an useful tool in the presurgical evaluation of epileptic patients. Homogeneous population of patients with unilateral or bilateral temporal foci with normal MRI are now being studied in our Center.

\section{REFERENCES}

1. Abou-Khalil BW, Siegel GJ, Sackellares JC. PET studies of cerebral glucose metabolism in chronic partial epilepsies. Ann Neurol 1987, 22:480-486.

2. Engel JJr, Babb TL, Phelps ME. Contribution of positron emission tomography to understanding mechanisms of epilepsy. In Engel $J$ (ed): Fundamental Mechanisms of Human Brain Function. New York: Raven Press, 1987, p 209-218.

3. Lee BI, Markand ON, Sidigui AR, Park HM, Mock B, Wellman HH, Worth RM, Edwards MK. SPECT brain imaging using HIPDM: intractable complex partial seizures. Neurology 1986, 36:1471-1477.

1. Ochs RF, Gloor P, Tyler JF. Effects of generalized spike-and-wave discharge on glucose metabolism measured by PET. Ann Neurol 1987, 21:458-464.

5. Sackhellares JC, Siegel JC, Abou-Khalil BW, Hood TW, Gilman S, McKeever PE, Hichwa RD, Hutchins GD. Differences between lateral and mesial temporal metabolism interictally in epilepsy of mesial temporal origin. Neurology 1990, 40:1420-1426.

6. Stefan H, Bocher_Schwarz HG, Biersack HJ, Burr W, Penin H, Heiss WD. Functional and môrphological abnormalities in temporal lobe epilepsy: a comparison of interictal and ictal EEG, CT, MRI, SPECT and PET. J Neurol 1987, 234:377-384.

7. Swartz BE, Halgren E, Delgado-Escueta AV, Mandelkern M, Gee M, Quinones $N$, Blahd WH, Repchan J. Neuroimaging in patients with seizures of probable frontal lobe origin. Epilepsia 1989, 30:547-558.

8. Theodore WH, Dorwart R, Holmes M. Neuroimaging in refractory partial seizures: comparison of PET, CT and MRI. Neurology 1986, 36:750-759.

9. Theodore WH, FishbeinD, Dubinsk R. Patterns of cerebral glucose metabolism in patients with partial seizures. Neurology 1988, 38:1201-1206. 